\title{
CRISIS Y REFORMA DEL MERCADO LABORAL ESPAÑOL. UNA PERSPECTIVA AUSTRIACA
}

\author{
LORENZO RAMÍREZ*
}

Fecha de recepción: 11 de septiembre de 2013.

Fecha de aceptación: 12 de marzo de 2014.

España ha sido tradicionalmente una economía con un elevado volumen de desempleo estructural que ni siquiera en los años de «bonanza» ${ }^{1}$ ha sido capaz de reducir la tasa de paro a niveles asumibles para cualquier país desarrollado. El elevado ritmo de creación de empleo que se produjo tras la entrada en el área de la moneda única concluyó — como siempre terminan las etapas de auge artificial - dando lugar a una crisis económica en la que se pusieron de manifiesto los errores cometidos por las familias y las empresas en materia de consumo e inversión, provocados por las falsas señales lanzadas desde los poderes públicos, especialmente en lo relativo a los tipos de interés y a las decisiones de gasto.

En este contexto, la adopción de las denominadas políticas de demanda contracíclicas no hicieron más que agravar los problemas, al obstaculizar el retorno de la economía al crecimiento sostenible, es decir, aquel que se produce en ausencia de intervención. ${ }^{2}$ Tal como nos advirtieron los padres fundadores de la

\footnotetext{
* Máster Oficial en Economía de la Escuela Austriaca, Universidad Rey Juan Carlos.

${ }^{1}$ El término «bonanza» es aquí usado como sinónimo de crecimiento del Producto Interior Bruto (PIB), que es el concepto en el que se basan la gran parte de los teóricos para determinar la evolución de la economía. Como veremos más adelante, en las sociedades actuales esta «bonanza» es solo un espejismo que, tarde o temprano, termina desvelando su cara real, ya que el crecimiento artificial se basa en la expansión crediticia que siempre acaba dando lugar, de forma inexorable, a una etapa de recesión económica con altos niveles de desempleo.

${ }^{2}$ Las fases de crecimiento económico sostenible están sustentadas en la generación de ahorro real por parte de los agentes económicos. Las variaciones en la oferta
} 
Escuela Austriaca de Economía, las expansiones fiscales y monetarias acometidas en las fases recesivas solo posponen los ajustes necesarios, obstaculizando la depuración de las malas inversiones y no permitiendo que los precios sobrevaluados de los activos retornen a sus valores reales previos a la formación de la burbuja monetaria. La sana recesión que debe seguir a todo proceso de crecimiento artificial no se produce y, por lo tanto, se mantiene la agonía de un sistema fallido en el que las decisiones de los agentes económicos están profundamente descoordinadas y en el que cada nueva intervención del Estado es una fuente de mayores problemas.

Aunque lo descrito no sucede solo en España, nuestro país es un claro ejemplo de cómo una errónea teoría económica puede destruir las bases de desarrollo de un país. Y no solo estamos hablando de aquellos burócratas que componen el cuerpo de la estructura política. Intelectuales y economistas versados en cualquiera de los enfoques que integran el Pensamiento único del mainstream ${ }^{3}$ repiten una y otra vez las falacias que han aprendido en sus estudios universitarios y que leen (y escriben) cada día en la prensa «especializada». El objetivo de este trabajo es desenmascarar la red de errores, falacias y mentiras que forman la tela de araña teórica en la que está atrapado el mercado laboral español y ofrecer un recetario básico de actuaciones que son indispensables para poder librar a la sociedad de los perversos efectos derivados de este conjunto de falsas teorías que ya fueron rebatidas hace más de cien años y que hoy sobreviven e, incluso, están resurgiendo aupadas por la propaganda socialista que sigue

de fondos prestables responden a cambios en el nivel de acumulación de ahorro (por ejemplo, un descenso de la tasa de preferencia temporal). En los procesos de crecimiento sostenible los tipos de interés libremente determinados en el mercado de fondos prestables permiten que la economía crezca de forma sana.

${ }^{3}$ Nos referimos aquí a las escuelas de pensamiento modernas, que carecen de una adecuada teoría del capital que les permita comprender el funcionamiento de la Economía. Los keynesianos y monetaristas en todas sus variantes han despreciado las aportaciones de la teoría del capital que diseñó y desarrolló el economista austriaco Eugen Böhm-Bawerk en el siglo XIX, discípulo del autor que puede considerarse el fundador de esta Escuela, el profesor Carl Menger. La gran mayoría de los economistas actuales obvia la naturaleza temporal del proceso productivo y, por lo tanto, no son capaces de ver el componente dinámico de los procesos de mercado. 
a toda crisis financiera. Los gobernantes crean los problemas, luego culpan al mercado y, finalmente, se atribuyen el «derecho»y el «deber» de intervenir en la vida de los ciudadanos poniendo en marcha de nuevo todo el proceso liberticida.

Mantener una estructura de teorías erróneas a lo largo de tanto tiempo ha sido posible gracias a la manipulación realizada por los ya citados intelectuales y economistas. Aunque no es un problema que afecte solo a España, en nuestro país se han generalizado una serie de posturas teóricas que apenas son rebatidas a pesar de estar basadas en burdos prejuicios contra el mercado. Los medios de comunicación sirven de altavoces para un conjunto de intelectuales que, en mayor o menor medida, manifiestan su oposición al sistema capitalista usando versiones modernas de la errónea teoría de la explotación laboral de factura marxista.

Lamentablemente no estamos hablando de nada nuevo. Hace más de un cuarto de siglo el economista francés Bertrand de Jouvenel ya explicó como ningún otro autor los motivos por los que los intelectuales «odian el capitalismo» ${ }^{4}$ y que se pueden resumir en tres: ignorancia (desconocimiento teórico de los procesos de mercado), soberbia (el intelectual se presenta como guía de lo «correcto" otorgándose un papel de maestro de la moral) y un resentimiento y envidia derivados de la no aceptación del beneficio como algo positivo que manifiesta el éxito del emprendedor a la hora de satisfacer las necesidades ajenas. La hipocresía de este tipo de intelectuales les hace alabar la acumulación de riqueza cuando la realizan organismos que llevan el sello del Estado, pero la demonizan si el capitalista es una entidad privada. En palabras de Jouvenel «el intelectual se considera un aliado natural del trabajador y esta alianza se concibe, como una alianza de armas. En la mente del intelectual está arraigada la imagen del hombre de pelo largo y del hombre de mono azul en las barricadas, uno junto al otro».

«Es casi un misterio - y un campo de investigación prometedor para historiadores y sociólogos- que la comunidad intelectual se hiciera más severa en sus juicios sobre el mundo de los

${ }^{4}$ Conferencia de Bertrand de Jouvenel, Los intelectuales europeos y el capitalismo. Publicado en Lecturas de Economía Política, volumen II (Unión Editorial, 1987). 
negocios precisamente cuando éste mejoraba de manera extraordinaria las condiciones de las masas, mejorando su propia ética de trabajo y aumentando su propia conciencia cívica ( ... ) Durante mucho tiempo se ha pensado que el gran problema del siglo XIX era el lugar que el trabajador industrial ocupaba en la sociedad y se ha prestado poca atención a la aparición de una amplia clase intelectual cuyo puesto en la sociedad puede ser el problema más importante».

Esta reflexión de Jouvenel debe servir a los escritores, profesores, periodistas y al resto de la comunidad intelectual para desterrar el odio endémico de la mayoría del establishment académico a la libertad económica y a la defensa del empresario como elemento coordinador entre los deseos de los consumidores y las aptitudes y conocimientos de los trabajadores, proceso dinámico de mercado que requiere del apoyo del capitalista para sacrificar bienes presentes por la promesa de bienes futuros, obteniendo una remuneración por la espera y el asumido.

\section{I \\ INTRODUCCIÓN: \\ LOS EFECTOS DE LA PLANIFICACIÓN \\ Y EL INTERVENCIONISMO}

Antes de continuar, como análisis introductorio, es necesario aclarar cuáles son los efectos de la planificación y del intervencionismo en una sociedad, mostrando la imposibilidad lógico-teórica del socialismo. Toda intervención en un mercado (en nuestro caso el laboral) tiene una serie de consecuencias derivadas del error intelectual socialista y se produce ante cualquier injerencia del poder político en la vida de los ciudadanos. Utilizando las palabras introductorias del profesor F.A. Hayek en su Camino de servidumbre ${ }^{5}$ hay socialistas en «todos los partidos» y es importante no confundir el término «socialismo» con el nombre que eventualmente tenga en una determinada época un movimiento político concreto.

${ }^{5}$ Escrito en 1944 y publicado en español por Unión Editorial, 2008. 
En nuestros días, fuera del ámbito económico - y en algunos casos incluso también dentro de los círculos académicos- se identifica el socialismo con su versión más aceptada en el terreno político de las democracias occidentales. Como ha demostrado a lo largo de toda su obra el profesor Jesús Huerta de Soto ${ }^{6}$ este socialismo democrático, o socialdemocracia, es tan dañino como su antecesor, el comunismo, a la hora de obstaculizar la coordinación de las decisiones intertemporales de los agentes y podemos afirmar, de hecho, que sustancialmente se trata del mismo concepto en esencia. Huerta de Soto ha demostrado teóricamente que el socialismo en todas sus vertientes evita el surgimiento de las tendencias coordinadoras de la sociedad, haciendo imposible el ejercicio de la función empresarial y destruyendo todos y cada uno de los elementos que han hecho posible la civilización y el desarrollo de la raza humana.

Sigamos entonces a Huerta de Soto en su definición de socialismo como «todo sistema de agresión institucional al libre ejercicio de la función empresarial». ${ }^{7}$ Es importante hacer notar que por agresión o coacción entendemos toda violencia física o amenaza creíble de violencia física. Como consecuencia de esta coacción, la persona no puede ejercer libremente su función empresarial y, para evitar males mayores, se ve forzada a actuar de una manera distinta a como habría actuado en ausencia de coacción. Es decir, que el actor modifica su comportamiento adecuándolo a los fines de aquel o aquellos que le coaccionan.

${ }^{6}$ Especialmente en Socialismo, cálculo económico y función empresarial (Unión Editorial, 1992).

7 «La función empresarial es inherente al ser humano y, en su sentido general, coincide con la acción humana misma, entendida como una característica esencial y eminentemente creativa de todo individuo que, al ejercerla, participa (sin ser consciente de ello) en un proceso de generación de información que desarrolla una serie de facultades coordinadoras que son las que espontáneamente hacen posible el surgimiento, el mantenimiento y el desarrollo de la civilización. En un sentido más estricto, la función empresarial consiste en crear, descubrir o apreciar las oportunidades de alcanzar algún fin, de localizar las posibilidades de ganancia o beneficio que se encuentran en el entorno, actuando en consecuencia para aprovecharlas. Desde este punto de vista, impedir el libre ejercicio de la función empresarial es la acción antihumana por excelencia. La agresión que implica el socialismo es un mal que impide que el ser humano desarrolle la actividad que le es más propia y que por esencia y de forma más íntima le corresponde», Jesús Huerta de Soto. 
Cuando se produce este tipo de agresión sistemática, es imposible que los seres humanos puedan descubrir y aprovechar las oportunidades de beneficio que tendrían si pudieran interactuar libremente con el resto de personas. De esta forma, no se crea ni transmite nueva información de unos actores a otros y, lo que es más relevante, no se produce el necesario ajuste en los casos de descoordinación social. La razón se encuentra en que, al no permitirse el libre aprovechamiento de las oportunidades de beneficio, no existe el incentivo necesario para que los seres humanos (en nuestro caso empresarios, trabajadores y capitalistas) se den cuenta de las situaciones de desajuste o descoordinación social que vayan surgiendo. Como consecuencia, los actores no aprenderán a disciplinar su comportamiento en función del resto de individuos y se impedirá que actúen las fuerzas coordinadoras que hacen posible la vida en sociedad.

Los defensores del socialismo carecen de la indispensable «caja de herramientas» teórica para llegar a las conclusiones que acabamos de exponer. Los estatistas de todos los partidos políticos defienden el intervencionismo porque creen que el sistema de coordinación social, no solo no se verá amenazado por la existencia de la coacción institucional o sistemática que proponen, sino que, por el contrario, piensan que la coordinación será mucho más efectiva si la agresión es ejercida por un órgano director (gobierno) que suponen dotado de unas valoraciones y conocimientos (en cuanto a los fines que deben perseguir los ciudadanos y los medios adecuados para alcanzarlos) mucho mejores que aquellos que poseen de forma individual los seres humanos coaccionados.

Esto plantea un problema de enormes dimensiones, ya que el socialismo pretende acabar con el problema de la descoordinación atacando al único elemento (la función empresarial) que permite que se produzca el proceso de coordinación de las conductas de los distintos seres humanos - unas en función de otras-que es imprescindible para el funcionamiento de la vida en sociedad; todo ello en un marco de constante descubrimiento y nueva creación de información práctica que haga posible el avance y desarrollo de la civilización.

El mercado laboral es uno de los más afectados por este proceso de agresión institucional que se realiza a través de los mandatos 
coactivos que emergen del poder político. Estas regulaciones, también conocidas de forma incorrecta como «leyes» en la sociedad actual, 8 son disposiciones o instrucciones de tipo concreto que, con independencia de cuál sea su apariencia jurídica formal, prohíben, ordenan u obligan a efectuar acciones determinadas en circunstancias particulares. Los mandatos resultan del diseño explícito y deliberado del órgano director y mediante ellos se pretende forzar a que todos los actores cumplan o persigan, no sus fines particulares, sino los fines de aquel que ejerce el poder. Sin embargo, lo que los intervencionistas desconocen es que este objetivo fundamental del socialismo no se puede cumplir, ya que es teóricamente imposible que el órgano encargado de ejercer la coacción disponga de la información necesaria para poder dar un contenido coordinador a sus mandatos.

Para demostrar la imposibilidad teórica del socialismo, Huerta de Soto considera indispensable señalar que, desde el punto de los seres humanos que interactúan entre sí, cada uno de ellos posee con carácter privativo una información práctica y dispersa que en su mayor parte es de naturaleza tácita y, por lo tanto, no articulable. Por las propias características de esta información, es lógicamente imposible concebir su transmisión a un órgano director, sea éste un departamento ministerial, una agencia pública estadística o cualquier otro organismo intervencionista. Es importante destacar que la imposibilidad de transmisión no solo tiene un carácter cuantitativo, derivado del infinito volumen de información que se encuentra en las mentes de los individuos, sino también,

8 Hayek opone al concepto de mandato el concepto de ley en sentido material, que es la norma abstracta de contenido general que se aplica a todos los seres humanos por igual sin tener en cuenta circunstancias particulares. En oposición a lo indicado para el mandato, la ley establece un marco dentro del cual es posible que cada actor cree y descubra nuevo conocimiento, y que pueda aprovecharse del mismo persiguiendo sus fines particulares en cooperación con los demás, y todo ello con independencia de cuáles sean dichos fines, siempre y cuando se cumpla la ley. A diferencia de los mandatos, las leyes no son creaciones deliberadas de la mente humana, sino que más bien tienen un origen consuetudinario, es decir, son instituciones que han ido formándose a lo largo de un período muy dilatado de tiempo como consecuencia de la participación de muchos individuos, cada uno de los cuales, mediante su comportamiento, ha ido incorporando a las mismas su experiencia e información. Ver F.A. Hayek, Los Fundamentos de la Libertad (Unión Editorial, 2008). 
y más importante, de carácter cualitativo, ya que este tipo de conocimiento tácito no articulable no puede ser expresado de una manera formal ni ser transmitido de forma explícita a ningún centro director. Y si la información relevante que necesita el planificador no puede ser obtenida, entonces los mandatos que de él emanen no tendrán facultades coordinadoras.

Una segunda demostración de tipo «dinámico» revela que el socialismo no solo es un error intelectual porque la propia naturaleza de la información relevante haga que ésta no puede ser transmitida, sino también porque los seres humanos al actuar (ejercer la función empresarial) constantemente crean o descubren nueva información que, cuando se produce la agresión institucional, no puede ser descubierta ni creada.

«Por lo tanto, como es obvio, es imposible que el órgano director pueda lograr hacerse con un conocimiento que no existe, ya que debe surgir como resultado del propio proceso social, siempre y cuando no se vea agredido por mandatos que impidan a los seres humanos perseguir sus propios fines y utilizar los medios que consideren más adecuados para ello. Todo organismo intervencionista se encuentra ante un dilema sin solución, ya que necesita la información que va generando el proceso social, información que en ningún caso puede lograr, pues si interviene coactivamente en tal proceso, destruye su capacidad creadora de información, y si no interviene, tampoco obtiene la información que necesita para dar contenido coordinador a sus mandatos», explica el profesor Huerta de Soto.

Siguiendo a Mises, ${ }^{9}$ el siguiente paso es demostrar la imposibilidad del socialismo desde el punto de vista del órgano director, admitiendo a efectos dialécticos y argumentativos, que está dotado de la máxima capacidad técnica e intelectual, experiencia y sabiduría, así como de las mejores intenciones que humanamente quepa concebir. Pero lo que en ningún caso podemos admitir que el órgano director tenga el don de omnisciencia, facultad que solo es atribuible a Dios. Por ello, existe una nula posibilidad de que el planificador pueda llegar a saber qué o cómo buscar los

\footnotetext{
${ }^{9}$ Ludwig von Mises, La acción humana (Unión Editorial, 2007).
} 
elementos de información dispersa que se van generando en el proceso social y que tanto necesita para controlarlo.

Además, no se puede olvidar que los intervencionistas son seres humanos de carne y hueso que tienen sus propios fines personales que actuarán como incentivos que les llevarán a descubrir el conocimiento relevante para sus objetivos particulares. Estos objetivos pueden ser, entre otros, mantenerse en el poder, justificar sus acciones ante sí mismos y ante terceros, ejercer la coacción de forma cada vez más sofisticada y efectiva, o presentar a los ciudadanos su agresión como algo inevitable y atractivo. ${ }^{10}$

Pero, volviendo al argumento misiano planteado hace ya casi un siglo, ${ }^{11}$ el órgano director siempre estará incapacitado para efectuar el cálculo económico necesario, en el sentido de que, con independencia de cuáles sean sus fines (y podemos suponer de nuevo que se trate de los fines más elevados moralmente) no podrá saber si los costes en los que incurre a la hora de perseguir dichos objetivos tienen para el propio órgano director un valor superior al valor que él mismo atribuye subjetivamente a los fines perseguidos.

En otras palabras, el planificador no puede conocer el coste de oportunidad de sus acciones (mandatos), pues la información

10 «En suma, puede considerarse que las aportaciones de la Escuela Austriaca, en general, y de la Escuela de Elección Pública (Public Choice), en particular, han dado lugar a un análisis más realista del proceso de gestión pública y de la actividad política, en el que se pone de manifiesto que detrás de cualquier decisión pública siempre existen individuos o personas concretas (y no misteriosos organismos o entes) que son los que toman las decisiones movidos por unos incentivos o motivos individuales muy concretos. Además, los estudios de estas escuelas han puesto de manifiesto que para que una decisión pública sea beneficiosa para la sociedad es preciso que exista una conexión entre aquellos que toman la decisión y los costes y beneficios que se deriven de la misma (concepto de "responsabilidad"). Está claro que en el mercado la gestión privada de los recursos a través de derechos de propiedad bien definidos garantiza una adecuada responsabilidad de las decisiones tomadas, mientras que en la democracia representativa se difumina y desaparece el nexo decisión-responsabilidad, por lo que no puede garantizarse a priori, y de hecho no sucede casi nunca a posteriori, que las decisiones tomadas sean las más adecuadas para el bien común». Jesús Huerta de Soto, Estudios de Economía Política, p. 240 (Unión Editorial, 1994).

11 En su artículo publicado en 1912 Die Wirtschaftsrechnung im Sozialistischen Gemeinwesen, cuya traducción al español podría ser «El cálculo económico en la comunidad socialista». 
sobre las circunstancias específicas de tiempo y lugar necesaria para estimar los costes se encuentra dispersa en las mentes de todos los seres humanos que sufren la coacción y, como ya hemos dicho, no puede ser descubierta ni creada por los propios actores en un entorno de agresión sistemática e institucional.

Y así, cerrando la línea argumental del profesor Huerta de Soto, volvemos al punto de partida de nuestra demostración teórica, concluyendo que el órgano planificador, con independencia de cuál sea su composición, sistema de elección y juicios de valor, como está incapacitado para ver y apreciar los costes en los que incurre, tenderá a actuar de forma irresponsable sin poder lograr los objetivos que persiga. Se da, por tanto, la irresoluble paradoja de que cuanto más se empeñe el órgano director en planificar o controlar una determinada parcela de la vida social, menos posibilidades tendrá de alcanzar sus objetivos, al no poder hacerse con la información necesaria para organizar coordinadamente la sociedad y creando, al mismo tiempo, nuevos y más graves desajustes y distorsiones cuanto más efectiva sea la coacción y más se limite la capacidad empresarial de los seres humanos.

Una vez demostrada la imposibilidad lógico-teórica del socialismo y las razones que hacen que sea un error intelectual, pasemos ahora a estudiar las consecuencias generales que se producen en las sociedades en las cuales los seres humanos se empeñan en establecer un sistema institucional de coacción que, en mayor o menor medida, restrinja el libre ejercicio de la acción humana. Posteriormente aplicaremos estas herramientas teóricas para diseccionar los problemas que han generado la crisis del mercado laboral español, aportando nuestra propuesta de reforma.

Como ya hemos planteado anteriormente, la primera consecuencia inexorable del socialismo es la aparición de una generalizada descoordinación o desajuste a nivel caracterizado por que múltiples agentes actúan de forma contradictoria, sin disciplinar su comportamiento en función de lo que hacen los demás y sin darse cuenta de que están cometiendo sistemáticamente errores de tipo sistemático. Esta frustración de planes individuales afecta a la esencia misma de la vida social y se manifiesta tanto intratemporal como intertemporalmente. El deseo voluntarista de «ordenar» la sociedad mediante mandatos coactivos es esencialmente 
generador de desorden, un hecho que se amplifica conforme el ámbito social es más complejo.

Paradójicamente, este desorden que generan las políticas intervencionistas suele ser utilizado como pretexto para justificar posteriores dosis de socialismo, con un nivel de agresión y control aún mayores. El órgano director atribuye a la «falta de colaboración» de los ciudadanos los desajustes sociales y les acusa de no cumplir correctamente sus mandatos, por lo que cada vez las órdenes se hacen más amplias, detalladas y coactivas. Esto es lo que explica la irresistible tendencia del socialismo hacia el totalitarismo, entendido como aquel régimen que aspira a intervenir en todos los órdenes de la vida.

Como colofón de este proceso de intervención, las medidas de intervención en las que se plasma el socialismo al final producen unos efectos o resultados sociales que suelen ser justo los contrarios de aquellos que se pretendía lograr por parte del propio órgano director. Este efecto autodestructivo del socialismo se denomina también "paradoja del intervencionismo o de la planificación» y, aunque es conocido desde hace tiempo, solo recientemente ha podido ser formulado en sus justos términos gracias a la teoría de la función empresarial.

El efecto inhibidor en la creación de la información práctica es más patente en el área económica. El socialismo crea y mantiene una generalizada mala inversión de los recursos y factores productivos que adquiere un carácter cíclico. Además, se produce un agudo problema de escasez, ya que la imposibilidad de calcular económicamente los costes lleva a dilapidar gran parte de los recursos en inversiones sin sentido, en un entorno en el que se elimina de raíz la enorme fuerza del ingenio empresarial para descubrir los estados de escasez y descubrir nuevas formas de eliminarlos. Estos errores en la asignación de recursos se hacen especialmente graves en el caso de la mano de obra, que tiende sistemáticamente a mal emplearse, surgiendo un elevado volumen de paro o desempleo, más o menos encubierto según la clase específica de socialismo del que se trate.

Pero antes de estudiar con detalle los efectos del intervencionismo en el mercado laboral utilizando como ejemplo el caso español mencionemos algunas consecuencias más que tiene la 
coacción institucional. El socialismo pone en marcha unos procesos que atraen y generan de forma sistemática información errónea o equivocada, dando lugar a comportamientos irresponsables que se generalizan, lo que añadido al carácter voluntarista y extensivo de la persecución de fines por parte del órgano director, tiene unas trágicas consecuencias sobre el entorno natural.

Además de este efecto destructor sobre el medioambiente, el socialismo también corrompe o desvía de manera perversa la fuerza de la función empresarial, ya que los seres humanos se dan cuenta de que tienen más posibilidades de lograr sus objetivos dedicando su ingenio a influir sobre los mecanismos de toma de decisiones de organismo planificador.

Como ha estudiado profundamente el profesor Hans-Hermann Hoppe, el socialismo crea un fortísimo incentivo para que los individuos pongan en marcha un proceso de lucha por el poder en el que el conflicto y la violencia sistemática entre los diferentes grupos es la nota más característica y dominante de la vida en sociedad. Por tanto, los seres humanos, como consecuencia del socialismo, pierden el hábito de comportarse moralmente (es decir, siguiendo principios o normas pautadas de acción) modificando su forma de actuar y su personalidad, que cada se muestra más amoral y agresiva.

En este contexto, las personas y grupos que no logren hacerse con el poder tendrán enormes incentivos para dedicar la mayor parte de su actividad a desviar los efectos más perjudiciales de los mandatos del órgano director. Tratarán de dar ventajas a aquellas personas encargadas de controlar y vigilar el cumplimiento de estos mandatos, realizando una actividad corruptora de tipo defensivo. Se trata de una especie de «válvula de escape» que permite una cierta reducción del daño social que produce el socialismo, permitiendo mantener algunos procesos coordinadores.

Finalmente, las personas y grupos que logren el poder tendrán como objetivo esencial de su actividad el mantenerse en esta posición. Según cual sea el tipo concreto de socialismo (totalitario, democrático, conservador o cientificista) variarán los detalles y peculiaridades de la actividad corruptora del poder, aunque el fin será el mismo: generar y estimular situaciones en los que el poder podrá aumentarse, extenderse y justificarse. Así, se dará 
privilegios a grupos que respalden al poder y se abusará de la propaganda, engañando a la población, distorsionando los hechos y creando crisis falsas, creando la artificial necesidad de la intervención.

En definitiva, el socialismo incita a violar la ley, la vacía de contenido y la corrompe, desprestigiándola completamente a nivel social y haciendo que los ciudadanos, como consecuencia pierdan todo respeto por ella. La moral a todos los niveles se debilita e incluso desparece siendo sustituida por un reflejo del misticismo organizativo del órgano de dirección. ${ }^{12}$ La deificación de la razón humana elimina todas aquellas instituciones sociales que hicieron posible el desarrollo de la civilización, arrojando al hombre, como dice Hayek, «a sus más primitivas pasiones». ${ }^{13}$

Como conclusión, el análisis teórico que hemos realizado en esta introducción, recopilando el trabajo académico del profesor Huerta de Soto, pone de manifiesto en la esfera moral, el socialismo corrompe los principios morales que constituyen las pautas de conducta que son imprescindibles para mantener el entramado social, desprestigiando e incitando a violar la ley, cuyo concepto se pervierte, y acabando con la justicia en su sentido tradicional.

En la esfera política el socialismo tiende inevitablemente hacia el totalitarismo, pues la coacción sistemática tiende a extenderse

12 Como recuerda el profesor Huerta de Soto en Socialismo, cálculo económico y función empresarial entre los máximos exponentes de esta perversión moral fruto del socialismo destaca John Maynard Keynes, uno de los mayores defensores de la coacción sistemática y del intervencionismo económico. En su libro Two Memoirs, citado por Hayek en Derecho, Legislación y Libertad (Unión Editorial, 1985), Keynes explica su postura «moral» de esta manera: «Rechazábamos de plano cualquier obligación de acatar normas generales. Proclamábamos el derecho a juzgar cada caso según sus propios méritos y nos creíamos en posesión de la sabiduría, la experiencia y el autodominio suficientes como para hacerlo de manera acertada. Se trataba de una parte esencial del credo que con violencia y agresividad defendíamos, actitud que, para los demás, era nuestra más ostensible e inquietante característica. Repudiábamos por completo la moral establecida, así como todo tipo de convención derivada del saber tradicional. Estábamos, pues, en el sentido más estricto del término, contra la moral. No reconocíamos la existencia de ninguna obligación moral ni sanción íntima susceptible de servirnos de guía. Reivindicábamos ante el cielo el derecho de ser jueces únicos de nuestra propia causa»; y añadía: «En lo que a mí concierne, es ya demasiado tarde para adoptar otra postura. Sigo y seguiré siendo contrario a los planteamientos morales.»

13 Ver F.A. Hayek, La fatal arrogancia (Unión Editorial, 1990). 
por todos los resquicios sociales destruyendo la libertad y la responsabilidad individual. En el plano económico, el socialismo impide y dificulta en gran medida la producción de bienes y servicios, y constituye, por tanto, un lastre para el desarrollo. En el área cultural el socialismo dificulta la creatividad, haciendo imposible el desarrollo y aprendizaje de nuevas pautas de comportamiento y dificultando el descubrimiento y la introducción de las innovaciones. Y en el campo científico, el socialismo no es sino un error intelectual, que tiene su origen en pensar que la capacidad de la mente humana es muy superior a la que realmente tiene y que, por tanto, es posible hacerse con la información precisa para mejorar coactivamente la sociedad.

En suma, el socialismo constituye la actividad antihumana y antisocial por excelencia, pues el mismo se basa en la coacción sistemática contra la más íntima y natural esencia del ser humano: su propia capacidad para actuar creativa y libremente. Una vez realizada esta demostración pasemos a analizar las causas y efectos de la intervención que se produce en un mercado concreto (el laboral) cuando es aplicada en el tipo más popular de socialismo en los tiempos actuales: el socialismo democrático o socialdemocracia. Este modelo ha abandonado su planteamiento original de nacionalizar todos los factores de producción, sustituyéndolo por una idea de agresión encaminada a la redistribución de la renta y la «igualación» de las oportunidades sociales. Es importante señalar que este tipo de socialismo solo se diferencia del socialismo real o comunismo en el grado, ya que cualitativamente son lo mismo: coacción institucional que no permite el libre ejercicio de la función empresarial.

II

EL SOCIALISMO EN EL MERCADO LABORAL

No existe un área en la economía — quizás con la excepción del sistema financiero- donde exista una mayor intervención del poder público que en el mercado de trabajo. Desde la llegada de la Revolución Industrial, el mito en el que se fundamenta la supuesta necesidad de que el Estado vele por las necesidades de los 
trabajadores, parte de la caracterización de los empresarios como agentes malvados sin escrúpulos que explotan a sus empleados a cambio de salarios lo suficientemente bajos como para que los trabajadores vivan en régimen de subsistencia en una práctica situación de esclavitud.

Este mito que sirvió a Marx y a sus seguidores para demonizar al sector privado y ensalzar las bondades del sector público, lejos de diluirse debido a su falta de rigor teórico, es el que esgrimen hoy en día los intervencionistas de todos los partidos para coartar la libertad de contratación e imponer unos precios que se derivan de la interacción entre oferta y demanda, generando un volumen de paro que, en el caso de España, supera ampliamente la cuarta parte de la población activa.

Como veremos a continuación, la coacción sindical e institucional, por un lado, y la expansión crediticia artificial que efectúa el sistema financiero, por el otro, son los dos grandes factores causantes del denominado desempleo «involuntario». De hecho, en ausencia de injerencias políticas, el paro involuntario no existiría, ya que la propia flexibilidad de los precios (salarios) haría que cualquier persona que quisiera trabajar pudiera encontrar empleo. Pero no adelantemos conceptos, en las próximas páginas nos ocuparemos de la coacción sindical e institucional que agrede a los agentes que operan en el mercado laboral español y, posteriormente, explicaremos los efectos que todo proceso inflacionario de creación de medios de pago sin respaldo de ahorro real tiene sobre la estructura económica de los países que la sufren.

Toca ahora analizar los objetivos que los legisladores españoles dicen perseguir mediante la intervención en el mercado laboral, así como las herramientas normativas (mandatos) que utilizan para ello. Después estudiaremos los efectos que tienen este tipo de injerencias en la economía como un caso particular de la teoría sobre la imposibilidad del socialismo y, finalmente, plantearemos propuestas de reforma para liberar las relaciones laborales del yugo de la coacción, permitiendo un desarrollo social en libertad, donde cada individuo sea responsable de sus actos y pueda elegir la mejor forma de atender sus necesidades, usando los medios que considere más adecuados para la obtención de sus fines particulares, logrando así una mayor coordinación social. 
La Constitución Española en su artículo 35 resume muy bien la mentalidad estatista y nos sirve para ilustrar cual es el objetivo de los poderes públicos que usan como coartada para justificar la intervención en el mercado laboral. En el citado artículo, la Carta Magna señala es deber del Gobierno garantizar que «todos los españoles tienen el deber de trabajar y el derecho al trabajo, a la libre elección de profesión u oficio, a la promoción a través del trabajo y a una remuneración suficiente para satisfacer sus necesidades y las de su familia». Esta aseveración parte de múltiples errores teóricos que es preciso aclarar para comprender el desarrollo normativo de este "derecho» ${ }^{14}$ que tienen los ciudadanos.

El punto clave de esta visión del trabajo como un «derecho» de las personas (y al mismo tiempo como un «deber») es considerar que los servicios del trabajo humano no están sometidos a idénticas leyes económicas que el resto de las mercancías y factores de producción. ${ }^{15}$ Como ya puso de manifiesto Ludwig von Mises, siguiendo la línea de investigación abierta por el fundador de la Escuela de Economía Austriaca, las leyes de la ciencia económica afectan de forma inexorable a todos los agentes que intervienen en el mercado - con independencia de cual sea el sentir popular sobre las mismas-, del mismo modo que la ley de gravedad o cualquier otra ley de la naturaleza, cuya existencia no podemos negar.

Pues bien, las dos leyes económicas que nos atañen en nuestro análisis del mercado laboral son, fundamentalmente, la ley de la oferta y la demanda y la ley que establece que el salario de los trabajadores está determinado por el valor descontado de la esperada productividad marginal del trabajo. Esta segunda ley

14 A pesar de que el artículo 35 está en el Título 1 de la Constitución) el derecho al trabajo ya una remuneración «adecuada» no es un derecho «fundamental» que esté sujeto a una especial protección en el ordenamiento jurídico español, al estar en la Sección Segunda de la Carta Magna, frente a los de la Sección Primera que sí lo están. El citado artículo también plantea que «la ley regulará un Estatuto de los Trabajadores» del que hablaremos posteriormente. Por otra parte, el derecho a sindicarse y a la huelga sí son derechos «fundamentales» que luego analizaremos.

15 Obviamente no nos referimos aquí a la persona humana en sí misma, la cual es indiscutiblemente alienable, tal como explica el profesor Jesús Huerta de Soto en su artículo «¿Es el trabajo una mercancía?», publicado en El Empresario, n. - 92, 2. ․ época, abril de 1985, p. 32. 
económica es vital para comprender el error de pensar en remuneraciones «adecuadas», «justas» o, como dice la Constitución Española «suficiente para satisfacer las necesidades del trabajador y las de su familia. En realidad, como explica Huerta de Soto (1985) el empresario paga al trabajador «el valor íntegro de lo que produce, pero calculando dicho valor en aquel momento en que se efectúe el trabajo y no cuando se ha completado temporalmente el proceso de producción».

Es decir, que, según nos dice la teoría económica, a los empleados se les paga por adelantado el valor descontado de lo que producen (a través del tipo de interés), lo que tumba la tesis marxista de la explotación que hoy es defendida por socialistas de todos los partidos. Si el empresario abonara al trabajador en el presente el valor íntegro de los bienes futuros que producirá, entonces le está remunerando como si no existiera la también ley económica de la preferencia temporal ${ }^{16}$ de los seres humanos, ni el riesgo inherente a toda actividad productiva.

Posteriormente, cuando estudiemos los efectos que provocan la intervención en el mercado laboral, demostraremos que cuando se incumplen estas leyes económicas y no se permite actuar al mercado mediante normas y restricciones institucionales (como las sindicales), el desempleo aumenta y perdura de forma indefinida.

Otro de los objetivos de la regulación española es garantizar el «derecho» a la denominada «libertad sindical» y a la huelga, ambos incluidos en el artículo 28 de la Constitución en su Sección Primera y, por ello, siendo considerados derechos «fundamentales». Es sintomático comprobar como el derecho a la propiedad, que es el fundamento y germen del orden social espontáneo (lo que F.A. Hayek denominaba Gran Sociedad) y que ha sido el elemento indispensable para el desarrollo de la civilización por medio de las relaciones de intercambio, está situado en la Carta Magna española un escalón por debajo del derecho a pertenecer a un

${ }^{16}$ El ser humano, siempre y en todo caso prefiere la satisfacción más próxima a la más remota, es decir, prefiere consumir en el presente a hacerlo en el futuro, o dicho de otra forma, en igualdad de circunstancias, valora más los bienes presentes que los futuros. 
sindicato. En materia sindical, la Constitución dedica otro artículo (el 37) a plantear otro objetivo de la intervención pública en el mercado laboral, al establecer que «la ley garantizará el derecho a la negociación colectiva laboral entre los representantes de los trabajadores y empresarios, así como la fuerza vinculante de los convenios».

Los principios intervencionistas planteados en la Carta Magna española fueron plasmados en 1980 en el Estatuto de los Trabajadores, norma que dio cobijo a los mandatos gubernamentales antes expuestos y que diseñó el marco en el que han transcurrido las relaciones entre trabajadores y empresarios hasta nuestros días. Aunque esta regulación ha sufrido modificaciones su esencia distorsionadora del mercado laboral permanece inalterada. Además, como apuntó en 2005 el entonces ministro de Trabajo, Jesús Caldera, cuando se cumplieron 25 años de la aprobación del Estatuto, esta norma «inauguró también una forma de hacer política social que, con los años, se ha convertido en la seña de identidad de nuestro sistema de relaciones de trabajo».

Antes de pasar al siguiente punto en el que explicaremos la justificación de la intervención del Estado en el mercado de trabajo, es indispensable utilizar las palabras de Jesús Caldera para exponer la importancia del concepto «social» en las políticas públicas económicas. Según la tesis socialista ${ }^{17}$ este término engloba a las medidas de intervención estatal que sirven para acabar con la desigualdad de la sociedad, redistribuyendo la riqueza y creando un sistema de protección para los ciudadanos que tienen un menor poder adquisitivo. Aquí se suele incluir el gasto en Sanidad, Educación, Seguridad Social. Planteado de esta forma, ¿quién podría negarse a aumentar el «gasto social»?

Sin embargo, como sucede con todas las políticas colectivistas, el impulso del «gasto social» es una gran trampa que acaba con

17 Aquí empleamos el término «socialista» en su sentido amplio. Tal como afirma el profesor Jesús Huerta de Soto en Socialismo, cálculo económico y función empresarial (Unión Editorial, 1992, p. 87) definimos el socialismo como «todo sistema de agresión institucional al libre ejercicio de la función empresarial». Como consecuencia de esta agresión (coacción) «la persona se ve forzada a actuar de una manera distinta a como habría actuado en otras circunstancias, modificando su comportamiento y adecuándolo a los fines de aquel o aquellos que le coaccionan». 
la poca capacidad de maniobra de la que disfrutan los ciudadanos. El socialismo utiliza al Estado, gracias a que se ha otorgado el monopolio de la violencia (con la policía y los tribunales) que financia mediante la política fiscal (con el cobro de impuestos), para cercenar las libertades individuales y atentar de forma sistemática contra los derechos de propiedad.

En este entorno ideológico, como considera Huerta de Soto (1985) «los ciudadanos pierden su libertad y quedan sometidos a las decisiones puramente subjetivas y arbitrarias del dictador económico del momento (haya sido o no democráticamente elegido)».

En definitiva y, como conclusión, podemos afirmar que la mejor política «social» no es la que se deriva de la intervención, sino la que deja en manos de los agentes económicos la elección de los medios y los fines para satisfacer sus necesidades.

Ya hemos avanzado algunos de los elementos que sirven a los gobernantes para justificar la adopción de políticas públicas laborales. La falsa interpretación del industrialismo - fuertemente viciada por los prejuicios anticapitalistas de políticos e intelectuales- ha provocado que la opinión pública considere que la subida de los salarios reales, la reducción de la jornada y la supresión del trabajo infantil, entre otros avances producidos en los últimos siglos, fueron gracias a la labor de los gobiernos y de los sindicatos, que se enfrentaron a los egoístas y explotadores empresarios y lucharon por la defensa de los intereses de los trabajadores.

Este error es vital para explicar toda posterior intervención en el mercado de trabajo. Como han estudiado en profundidad autores como los ya citados Mises y Hayek, así como Bertrand de Jouvenel $^{18}$ o William Hutt, ${ }^{19}$ el desarrollo industrial amplió las existencias de capital en una proporción muy superior al aumento de la población, lo que ha permitido que el nivel de vida de la población se haya elevado de forma notable. De hecho, la organización capitalista ha beneficiado a los trabajadores a pesar de que

18 Los intelectuales europeos y el capitalismo, publicado en El capitalismo y los escritores (Unión Editorial, Madrid 1973, pp. 93-121).

19 El sistema de la fábrica a principios del siglo XIX publicado en El capitalismo y los escritores (Unión Editorial, Madrid 1973, pp. 157-183). 
éstos han hecho todo lo posible por impedir la implantación de aquellos sistemas que tanto han aumentado el nivel de vida.

Por lo tanto, el argumento fundamental que emplean los burócratas para justificar la intervención en el mercado laboral parte de una premisa falsa. No es la legislación «social», ni la regulación laboral (ni la actividad sindical) lo que ha provocado los avances antes mencionados, sino que ha sido el mercado (la libre interacción de los individuos) el responsable de estas conquistas, a pesar de haber tenido que luchar contra la eterna oposición de la injerencia gubernamental. ${ }^{20}$

Lo que garantiza la mejora continuada del nivel de vida de los trabajadores es el ahorro y la inversión en bienes de capital «dentro de un sistema de libertades que permita negociar unos salarios compatibles con el pleno empleo y que minimice los costes artificiales a la contratación. No se trata de que no haya unas condiciones mínimas en el mercado, sino que esas condiciones vienen limitadas por el grado de desarrollo económico. Si el Estado burla esos límites, ( ... ) tenderá a provocar distorsiones que generalmente se traducirán en un incremento del desempleo». ${ }^{21}$

La jerarquía normativa que forma el conjunto de mandatos aplicables a las relaciones laborales en España se encuentra contenida en las normas que a continuación se detallan y que figuran ordenadas de mayor a menor rango:

- La Constitución Española.

- Los Tratados y Convenios internacionales.

- Las Leyes Orgánicas.

- Las Leyes Ordinarias, Decretos Legislativos y Decretos leyes.

20 Es importante recordar que el mercado laboral, como cualquier otro mercado, es un proceso social impulsado por la fuerza de la empresarialidad, compuesto por empresarios capitalistas y por empresarios trabajadores que descubren oportunidades de ganancia en los desajustes inherentes a todo orden social. Entre ambos colectivos hay espacio para los intermediarios, aunque en la actualidad el Estado no permita su expansión. El trabajo es un factor de producción escaso y, como tal, se compra y se vende en el mercado. Y, por ello, es necesario dejar que la iniciativa privada intermedie para, buscando oportunidades de negocio, permita que empresarios y trabajadores se encuentren y puedan realizar intercambios.

21 Juan Ramón Rallo, El mercado de trabajo, publicado en Un modelo realmente liberal (LID, 2012, p. 155). 
- Los Convenios Colectivos y los convenios de empresa.

- Las Ordenanzas Laborales o Reglamentaciones de trabajo.

- El contrato de trabajo.

- Los usos y las costumbres locales y profesionales.

- Los principios generales del derecho.

Como hemos explicado al comienzo de este apartado, la Constitución Española es la norma de más alto rango y a ella se subordinan todas las demás. Las cuestiones relativas al orden laboral están contenidas en los Capítulos II (derechos y libertades) y III (principios rectores de la de la política social y económica), y contiene como derechos fundamentales de índole laboral el derecho a sindicarse libremente y a la huelga de los trabajadores en defensa sus intereses.

Las leyes estatales se dividen en leyes orgánicas, relativas a derechos fundamentales, Leyes ordinarias, regulan todas las materias salvo aquellas reservadas a las anteriores, los Decretos-Leyes, disposiciones legislativas dictadas por el Gobiernos en casos de necesidad urgente y extraordinaria, los Decretos Legislativos, los reglamentos, que desarrollan las leyes, etc. En este marco normativo se encuadra el Estatuto de los Trabajadores, cuya primera redacción es de 1980.

La competencia para legislar en materia laboral está atribuida de forma exclusiva al Estado por lo que las comunidades autónomas tan solo pueden ejecutar las normas dictadas por el Gobierno central.

En caso de dudas en la aplicación de las normas laborales, la aplicación e interpretación de las mismas se hará teniendo en cuenta cuál es la norma o condición más favorable para el trabajador.

El convenio colectivo es el acuerdo suscrito entre los representantes de los trabajadores y de los empresarios para fijar las condiciones de trabajo y productividad en un ámbito laboral determinado. Para tener validez, los convenios tienen que celebrarse por escrito y ser presentados ante la autoridad laboral siendo aplicables desde el momento en el que así lo acuerden las partes.

El convenio colectivo, entre otros, puede regular contenidos económicos y laborales. Los primeros hacen referencia a cuestiones relativas al salario o cualquier otro tipo de remuneración tales 
como su cuantía, complementos salariales, o el importe de las horas extraordinarias. En cuanto a los segundos incluyen las condiciones laborales tales como la jornada diaria, semanal y anual de trabajo, los descansos semanales, las categorías profesionales, la duración y tipos de contratos de trabajo el rendimiento exigible a los trabajadores, el contenido de faltas y sus sanciones.

Además, el convenio colectivo puede establecer las relaciones entre los trabajadores y sus organizaciones, medidas de prestación asistencial y de promoción profesional, la forma y plazos del preaviso previo a la extinción de la relación laboral, etc. Por su parte, el convenio de empresa tendrá prioridad sobre el convenio colectivo en las siguientes materias:

En cuanto a los tipos de contratos, pueden clasificarse en dos categorías: contratos por tiempo indefinido y contratos temporales. En los primeros se incluirían los contratos a tiempo parcial (si la relación es indefinida), y los indefinidos ordinarios e indefinidos de fomento del empleo; en el segundo grupo todos los demás. No es el objetivo de este trabajo profundizar en el análisis de toda la tipología 22 de contratos que existen en España, baste decir que hay casi una veintena de ellos y que algunos establecen bonificaciones a la hora de contratar a determinados colectivos, tales como jóvenes, desempleados, parados de larga duración, minusválidos, etc.

Una vez explicados los objetivos que tiene el órgano director (gobierno) para intervenir en el mercado laboral, así como los mandatos que usa como herramientas para ejercer la agresión institucional sistemática, es ahora el turno de estudiar los perniciosos efectos que tiene la coacción en este mercado. Para ello es necesario recuperar las dos leyes económicas fundamentales en esta materia: la ley de la oferta y la demanda, $y$, por otra parte,

22 Contrato indefinido, contrato indefinido de fijos-discontinuos, contrato de minusválidos, contrato para el fomento de la contratación indefinida, contrato para la formación, contrato en prácticas, contrato temporal para trabajadores desempleados en situación de exclusión social, contrato de obra o servicio determinado, contrato eventual por circunstancias de la producción, contrato de interinidad, contratación en sustitución por anticipación de la edad de jubilación, contrato de relevo, contrato a tiempo parcial, contratos de inserción, contrato de trabajo de grupo, contrato de trabajo a domicilio. Fuente: Ministerio de Empleo y de Seguridad Social. 
la ley de fijación del salario en función de la esperada productividad marginal del trabajo.

Tal como puso de manifiesto Mises $^{23}$ el principal hecho que afecta a la oferta de trabajo es la desutilidad del mismo. Es decir, el ser humano prefiere - en igualdad de circunstancias- no trabajar (sin analizar factores psicológicos como la alegría o el fastidio, que no influyen en la oferta laboral). Y cuando trabaja lo hace por una remuneración y no de forma ininterrumpida hasta agotar totalmente su capacidad, sino que «deja la faena tan pronto como deja de compensarle la gratificación mediata que el trabajo le debe proporcionar respecto a la desutilidad del trabajo adicional».

En cuanto a la demanda de trabajo, viene determinada por las necesidades que tengan los empresarios en un determinado momento y lugar, que a su vez genera una estructura productiva con diversas etapas. El trabajo es un factor de producción más que debe emplear el empresario para poder satisfacer de la mejor manera posible las necesidades de los consumidores. Si cumple con este objetivo tendrá beneficios y, en caso contrario, tendrá pérdidas.

El salario (precio del factor de producción) en el mercado libre, tiende siempre a igualarse con las productividad marginal del trabajo, es decir, con el valor que para el mercado tiene el aumento o la reducción de la producción que resultaría de que el empresario contratara un empleado más o lo despidiera. ${ }^{24} \mathrm{~A}$ ese salario (precio) todo aquel que busque fuerza laboral la encuentra, y quienes desean trabajar también logran cumplir sus objetivos.

23 Ludwig von Mises, La acción humana (Unión Editorial,)

24 «Si se pagase al trabajador una cantidad inferior al valor descontado de la productividad marginal esperada, aumentarían los beneficios del empresario si éste demandase y contratase más trabajadores, produciéndose de esta forma una tendencia a incrementarse los salarios y a disminuir la productividad hasta hacerse unos y otra prácticamente iguales. Lo contrario sucede en caso de que el salario exceda a la productividad: se despiden o se dejan de contratar trabajadores hasta que la productividad aumenta y los salarios disminuyen convenientemente (si, como consecuencia de leyes laborales y restricciones institucionales de todo tipo, este reajuste no se produce en el mercado, el paro se incrementa y perdura de forma indefinida, tal y como sucede hoy en día en nuestro país, donde existen más de tres millones de parados por culpa de la no existencia de mercados laborales suficientemente libres)». Jesús Huerta de Soto, ¿Es el trabajo una mercancía? 
Podemos concluir, por tanto, que la remuneración de todo empleado está determinada por el valor que la gente atribuye a la obra o servicio que realiza, lo que supone el sometimiento de aquel que le contrata a la supremacía del consumidor. Cada empresario procura adquirir el trabajo que precisa al precio más barato Posible, pero lo suficientemente alto como para que al trabajador le compense la desutilidad $y$, al mismo tiempo, le permita atraer al empleado frente al resto de empresarios.

Estos son los únicos límites que existen al salario en un mercado libre: el superior se halla prefijado por el precio a que el empresario piensa que podrá vender las cantidades de la producción logradas gracias a un nuevo trabajador contratado; mientras que el inferior lo determinan las ofertas del resto de empresarios que compiten por la contratación de los servicios laborales.

El salario mínimo intenta proteger a los trabajadores del «abuso» de los empresarios, pero lo que en realidad consigue es una infinidad de desempleados. Especialmente entre los trabajadores más desfavorecidos como los jóvenes o aquellos que se integran por primera vez en el mercado laboral, ya que su productividad es menor que el salario mínimo que deben percibir por ley, por lo tanto nadie va a darles trabajo. Es tan complicado contratar a alguien en España que no es de extrañar los niveles de desempleo que sufrimos.

Las fuerzas del mercado que hacen que el salario que reciba el empleado tienda a ser igual a su productividad marginal, mediante la competencia entre los empresarios se aplican aún en el caso de los trabajadores desconozcan los salarios ofrecidos en otros lugares, o vivieran en zonas incomunicadas sin alternativas de empleo. No es necesario que ambas partes de un contrato tengan conocimiento de todas las condiciones relevantes.

Los teóricos del paradigma neoclásico-walrasiano dicen que, a menos que ambas partes estén igual de bien informadas, se da una "competencia imperfecta» que provoca que las leyes económicas no sean aplicables. Pero no es así. Los trabajadores no suelen tener un conocimiento global del mercado laboral, mientras que los empresarios están presumiblemente mucho mejor informados. Y no hace falta más. "Aunque el trabajador no esté bien informado acerca de otras oportunidades de trabajo, sabe 
perfectamente que debe aceptar el trabajo mejor pagado. Todo lo que hace falta es que el patrón localice al empleado que está ganando una cantidad menor a su productividad marginal y le ofrezca un salario mayor». ${ }^{25}$

Y exactamente esto es lo que ocurre de forma natural. El interés personal de los patrones les lleva «como dirigidos por una mano invisible» ${ }^{26}$ a localizar los trabajadores mal pagados, ofrecerles salarios más elevados y llevárselos a sus empresas. Este proceso tiende a elevar los salarios hasta que alcanzan el nivel de productividad marginal, y no solo se aplica a las ciudades, sino también a los lugares aislados en los que los trabajadores desconocen otras oportunidades de trabajo y, en caso de conocerlas, no tendrían dinero suficiente para desplazarse. El profesor Walter Block considera a este respecto que «está claro que la diferencia entre el salario y la productividad del empleado sería lo suficientemente grande como para que el patrón amortizase los gastos de dirigirse hasta allí, informar al empleado de las alternativas de trabajo y pagarle los costes del traslado. Hace tiempo que los patrones son conscientes de que esta práctica casi siempre funciona.

Por todo lo expuesto, cuando como consecuencia de la decisión de un Gobierno debido a la presión sindical, se establece un determinado salario mínimo por debajo del cual no se permite a los empresarios contratar trabajadores, lo que se provoca es desempleo, que denominamos «institucional». 27

Este paro no es fruto de la decisión de los individuos, ${ }^{28}$ sino de la injerencia en los fenómenos de mercado que tienden a formar,

25 Walter Block, Defendiendo lo indefendible (Unión Editorial/ Innisfree, 2012).

26 Expresión que popularizó Adam Smith en su Riqueza de las Naciones (1776).

27 Para diferenciarlo del paro cataláctico (también denominado «friccional»o «voluntario») que es el que se produce de forma natural cuando los agentes económicos optan entre el empleo y el paro. En el mercado libre existe para todo trabajo un cierto salario por el cual todo el que busca trabajo lo encuentra. Es a través de la variabilidad y la disparidad salarial como se manifiesta en el mercado laboral la soberanía de los consumidores, permitiendo repartir la capacidad laboral entre las distintas ramas de la producción.

${ }^{28}$ Cuando se fijan salarios mínimos «se condena al paro y a la desesperación a todos aquellos trabajadores que, por producir un valor inferior al salario establecido legalmente, no pueden encontrar trabajo». Jesús Huerta de Soto, ¿Es el trabajo una 
mediante la coacción y la compulsión, tipos de salario superiores a los que fija el mercado (así como condiciones laborales distintas a la que se ofrecerían en un entorno de libre mercado). Se obstaculiza así el proceso social necesario para encontrar los acuerdos más satisfactorios entre trabajadores y empresarios, perjudicando a ambos y, por extensión, a los consumidores.

Block lo explica con estas palabras: «La Ley de Salario Mínimo no es una ley de empleo, sino de desempleo, pues no obliga al patrón a contratar a un empleado con el salario mínimo, sino que le obliga a no contratar a empleados con determinados salarios, es decir, con salarios inferiores a los estipulados por ley. Esta ley coacciona al trabajador a no aceptar un trabajo que ofrezca un salario por debajo del mínimo, independientemente de lo ansioso que esté por aceptar cualquier trabajo. La ley no impulsa una subida salarial, sino que se limita a dejar fuera todos aquellos trabajos que no cumplen con los estándares.»

Son las fuerzas mercantiles y el empeño de los empresarios en maximizar sus beneficios los factores que aseguran de que los salarios no descienden por debajo del nivel de productividad. Un nivel de productividad que está determinado por la tecnología, por la educación y el conjunto de bienes capitales de una sociedad, no por el conjunto de leyes «socialmente progresistas» promulgadas. La ley de salario mínimo no hace lo que sus defensores proclaman. De hecho, siguiendo el argumento de Block, si se aplica una ley de salario mínimo en un determinado país, el empresario querrá despedir a todos los trabajadores a los que esté obligado a subir el sueldo (un sueldo que habría subido igualmente si no le hubieran obligado a ello), pues su deber será mantener la productividad, y no podrá ajustarse a la situación de forma inmediata. Pero con el paso del tiempo sustituirá a sus trabajadores no especializados que inesperadamente se han vuelto caros por menos trabajadores pero más cualificados y con maquinaria más sofisticada, de forma que su productividad se mantenga constante.

"Cualquier estudiante de un curso de introducción a la economía aprenderá que, cuando un nivel de precios se sitúa por

mercancía? Se podría decir que la legislación laboral prohibe ganarse la vida a los trabajadores menos productivos. 
encima del equilibrio, se da un excedente. ( ... ) Por iconoclasta que pueda sonar, es cierto que la ley de salario mínimo genera desempleo. Un mayor nivel salarial [artificial provoca que haya más gente que quiera trabajar pero menos trabajos disponibles». Y esta afirmación no necesita ninguna demostración estadística para comprobar su veracidad, ya que procede de una ley económica válida en todo tiempo y lugar. Sin embargo, para contentar a todos aquellos teóricos que siguen impregnados de la fiebre empírica, el profesor Block añade que cuando la ley estadounidense del salario mínimo subió de 40 a 75 centavos la hora el salario de los ascensoristas éstos fueron sustituidos. Llevó algo de tiempo, pero ahora la mayoría de los ascensores son automáticos. Lo mismo ocurrió con los friegaplatos no especializados: han sido y siguen siendo reemplazados por máquinas lavavajillas, que son manipuladas y reparadas por trabajadores especializados y semiespecializados. Y el proceso continúa.

Es vital comprender, como plantea William Hutt ${ }^{29}$ que la política discriminatoria y coactiva de los sindicatos no se limita a la exclusión patente, mediante restricciones en el acceso al aprendizaje y otros métodos semejantes. «El empeño en lograr salarios artificialmente altos tiende a reducir el número de trabajadores que resulta provechoso emplear, con lo que los sindicatos se benefician a costa de los demás. Este método para disfrutar de un monopolio resulta más pernicioso que el de la exclusión del aprendizaje, pues los monopolistas aseguran obrar en interés de aquellos a quienes de hecho excluyen ( ... ) Los males del monopolio sindical no residen solo en que empujan a los menos afortunados a ocupaciones relativamente mal pagadas, sino a que ello viene a sumarse el aumento del coste de la vida que su política provoca».

Además de la fijación de salarios mínimos, otra forma de intervenir los precios en el mercado laboral son los impuestos y las cotizaciones que pagan trabajadores y empresarios a la Seguridad Social para mantener el sistema público destinado al pago de prestaciones por desempleo y a las pensiones de los jubilados.

${ }^{29}$ La contratación colectiva (Unión Editorial 1976). 
El efecto de estas cargas fiscales es muy pernicioso también, ya que los salarios brutos (que son el resultado de sumar a la remuneración que recibe el trabajador los impuestos y cotizaciones) tienden siempre hacia el punto en el que se igualan con el precio al que puede venderse en el mercado el incremento de la producción logrado mediante un trabajador adicional (la productividad marginal), una vez deducido el coste de los materiales y del interés sobre el capital invertido.

Esto quiere decir, que cuando las leyes obligan a los empresarios a pagar desembolsos adicionales al salario neto que recibe el trabajador, éstos se computan como parte del coste laboral, integrando la cuantía del salario bruto. Es decir, que quien paga realmente todas las cargas y beneficios denominados «sociales» es el empleado, a través de la reducción del salario neto que recibe. ${ }^{30}$

Otro aspecto importante del efecto devastador que tienen, en general, todas las regulaciones de redistribución de la renta es el hecho de que este tipo de políticas públicas empobrecen a las masas al provocar una bajada general de los salarios reales como consecuencia de la menor acumulación de capital disponible por trabajador que este tipo de leyes motivan. Siguiendo la explicación de Mises ${ }^{31}$ cuando existe acumulación de capital con mayor rapidez que el incremento de la población, tanto la productividad marginal del trabajo como los salarios y el nivel de vida de los trabajadores tienden al alza continua. Este progreso es un efecto provocado por un conjunto de factores que solo bajo el régimen capitalista pueden darse. Por eso es tan criticable que tantos gobiernos se obstinen en ahuyentar y dilapidar el capital con leyes fiscales confiscatorias.

Por lo que se refiere a los convenios colectivos, las políticas sindicales de logro de aumentos salariales por medios coactivos tienen siempre el mismo resultado: los trabajadores que conservan

30 En España, además del citado salario mínimo interprofesional, el cual se sitúa en los 752 euros mensuales, la jornada laboral semanal está limitada por ley a 40 horas y existe Hay que añadir que tenemos impuesto para la Seguridad Social (payroll tax) del $31,6 \%$ que abona directamente el empresario mientras que el trabajador paga un $6 \%$ adicional. Conclusión: el coste de contratación es altísimo.

${ }^{31}$ Ludwig von Mises, La acción humana (Unión Editorial,) 
sus empleos son favorecidos a costa de aquellos que están obligados a trabajar a un salario inferior al que habría en un entorno de mercado libre o a permanecer desocupados. Este fenómeno se podría calificar de explotación horizontal realizada por trabajadores privilegiados ${ }^{32}$ que conservan sus puestos de trabajo en unas condiciones de las que nunca podrían disfrutar sin la intervención en perjuicio de millones de parados.

Otro de los problemas es la fijación de indemnizaciones por despido que no permiten que haya libertad a la hora de fijar las condiciones en los que trabajador y empresario pueden poner fin a su relación laboral. En España, tanto las causas como la cuantía de la indemnización están fijadas por la regulación. En este caso el efecto es similar al que ya hemos analizado relativo a las cargas fiscales y las cotizaciones sociales. La indemnización por despido es un coste laboral más. Por mucho que se rebaje su cuantía mediante sucesivas reformas (la más reciente es de 2012) el problema sigue siendo el mismo. «Imponer una indemnización universal por despido supone regular en qué forma se cobra el salario y qué derechos adicionales conlleva y eso es una decisión que no debería corresponder ni a políticos ni a sindicatos». ${ }^{33}$

Finalmente, otro elemento que eleva el coste laboral es la obligación de financiar los denominados «liberados sindicales» cuya función oficial es defender los «derechos» de los trabajadores ante

32 William Hutt recuerda que uno de los primeros autores que denunció la existencia de una «aristocracia sindical» que perjudica los intereses de los trabajadores que dice defender fue uno de los menos sospechosos de ser enemigo de las instituciones obreras. William Thompson (1775-1833), al que Carl Menger considera «el más eminente entre los fundadores del moderno socialismo científico» y padre de la idea de "plusvalía», fue un hombre apacible que solo le hacía perder los estribos lo que denominaba «aristocracias sangrientas», refiriéndose a los privilegiados sindicales que ejercían la coacción sobre el resto de los trabajadores. Thompson señalaba ya en 1827 que «no importa si esa coacción es concesión de la ley o los trabajadores la emplean pese a ella, porque siempre será coacción». Además, a su juicio, «los sindicatos evidencian la ineficacia de las disposiciones forzosas, aun cuando las respalde el poder político, en cuanto a elevar en todo el país la remuneración de cualquier tipo de trabajo; aunque sin duda han tendido a elevar la de unos pocos privilegiados que entran en el acuerdo a expensan del derecho de todos los trabajadores a ofrecer su trabajo donde y como quieran».

33 Juan Ramón Rallo, El mercado de trabajo, publicado en Un modelo realmente liberal (LID, 2012). 
la dirección de la empresa. En realidad, tal como hemos comentado, su trabajo consiste en mantener la explotación horizontal que efectúan los trabajadores privilegiados no productivos sobre los demás. Y, además, estos «liberados» usan los recursos de los empresarios para su propio beneficio y los del sindicato al que pertenecen. Estos representantes son pagados de forma coactiva por todos los empleados, quieran o no quieran sus servicios, elevando el coste laboral de toda la plantilla y, por ende, reduciendo los salarios.

La misma crítica debe hacerse de las subvenciones que reciben los sindicatos del sector público, tanto las derivadas de su actividad principal como aquellas específicas, como el impartir cursos de formación para los desempleados y otro tipo de actividades. Y esta consideración debe hacerse extensiva a las patronales, que privilegian a determinados empresarios sobre el resto y se convierten defacto en un sindicato de empresarios que también aplican una especie de explotación horizontal sobre aquellos emprendedores no privilegiados.

En resumen, podemos decir que las intervenciones públicas en el mercado laboral se basan en actuar sobre el precio de mercado del factor de producción que proporciona servicios laborales, lo que siempre genera distorsiones y tiende a provocar desempleo endémico o estructural. Lo paradójico es que, aunque muchos gobernantes e intelectuales no lo sepan, la ley económica que advierte de los riesgos de alterar los precios de mercado ya fue descubierta hace varios siglos.

Como señala Murray Rothbard ${ }^{34}$ el escolástico español Martín de Azpilicueta (1493-1586) «fue el primer pensador económico que afirmó tajantemente que la fijación de precios por el gobierno era algo imprudente y temerario ( ... ) con gran sensatez advirtió que cuando los bienes son abundantes no hay necesidad alguna de fijar un precio máximo y que cuando son escasos, los controles causarían a la comunidad más perjuicio que beneficio».

${ }^{34}$ Murray N. Rothbard Historia del pensamiento económico, vol. 1, p. 136 (Unión Editorial 1999). 


\section{III INFLACIÓN Y DESEMPLEO}

Llegados a este punto, toca ahora referirse a la principal causa del desempleo en el mundo moderno: la inflación. Antes de comenzar es necesario aclarar que el término «inflación» es usado de forma errónea por la totalidad de los medios de comunicación y la inmensa mayoría de los economistas, ya que cuando emplean este concepto se refieren al aumento de los precios en un determinado periodo. De hecho, la Real Academia de la Lengua Española (RAE), en su cuarta acepción, agudiza el problema al definir «inflación» como «elevación notable del nivel de precios con efectos desfavorables para la economía de un país». La Academia comete así el pecado intelectual de confundir la causa con el efecto, ya que, en realidad, la subida de los precios (relativos y nunca de forma homogénea, al contrario de lo que piensan los monetaristas) es la consecuencia de la inflación y no su elemento esencial definitorio.

En su sentido correcto, inflación ${ }^{35}$ es el aumento de la oferta de medios de pago que se produce en las sociedades donde el Estado ha expropiado el dinero privado (que tradicionalmente ha sido el oro y otros metales) sustituyéndolo por dinero fiduciario. Este proceso se hace fundamentalmente a través de la monetización del déficit público, de la expansión crediticia que realizan las entidades financieras bajo la batuta de los bancos centrales, y mediante intervenciones de los citados bancos centrales en los mercados de activos, como las operaciones de mercado abierto.

El análisis de la inflación y de sus efectos es una de las características esenciales de la Escuela Austriaca de Economía y se deriva de los sólidos cimientos teóricos construidos en torno a una

35 «Mucha de la confusión existente se deriva del inapropiado uso del término inflación. Su original y correcto significado se refiere al incremento de los medios de pago; lo que en igualdad de otras circunstancias, dará lugar a un alza de precios. No es inflación un generalizado incremento de precios que, por ejemplo, sea consecuencia de las escaseces provocadas por una mala cosecha a no ser que, con motivo de las correspondientes dificultades políticas, el gobierno haya decidido incrementar la oferta monetaria». F.A. Hayek, Inflación o pleno empleo (Unión Editorial, Madrid 1976, cap. II). 
visión subjetivista que huye de los agregados y que dispone de una teoría del capital que explica cómo todo proceso productivo se lleva a cabo no como consecuencia de la participación de un misterioso fondo homogéneo (como pensaba John Bates Clark, primero, y luego los monetaristas de la Escuela de Chicago con su fundador, Frank Knight, al frente), sino como resultado de la cooperación de bienes de capital concretos que siempre han de ser previamente concebidos, producidos, seleccionados y combinados por los empresarios dentro del proceso económico.

Como bien explica Huerta de Soto, la concepción mítica del capital (como fondo que se mantiene por sí mismo, en un proceso productivo que no conlleva tiempo) «impide que sus teóricos comprendan las íntimas relaciones que existen entre el lado micro y el lado macro de la economía, pues la conexión entre ambos viene constituida, precisamente, por los planes temporales de empresarios creativos que, por definición, son eliminados del modelo walrasiano ${ }^{36}$ del sistema económico que Clark y Knight incorporan en su teoría del capital». ${ }^{37}$

A este respecto, el profesor F.A. Hayek señala que todos los economistas que carecen de una adecuada teoría del capital no son capaces de darse cuenta, en general, de cuáles son los problemas económicos relevantes en la vida real, y en particular de qué manera la estructura productiva varía ante un crecimiento o un decrecimiento del ahorro voluntario y se ve afectada como consecuencia de la expansión crediticia.

Usando las palabras de Hayek, los teóricos monetaristas se fijan solamente en el nivel general de precios y «adolecen de una incapacidad consustancial para descubrir los efectos que sobre la estructura relativa de los precios produce una expansión de los medios de pago disponibles». No contemplan, por ello, las consecuencias más graves del proceso inflacionario: la mala inversión de recursos y la generación del correspondiente paro laboral.

36 «El modelo de equilibrio general de Leon Walras (1834-1910) es un modelo estrictamente estático que no recoge el transcurso del tiempo y que describe de una manera sincronizada interrelaciones mutuas entre diferentes variables y parámetros que nunca surgen de manera simultánea en la vida real», Jesús Huerta de Soto, Dinero, crédito bancario y ciclos económicos (Unión Editorial, 1998).

37 Dinero, crédito bancario y ciclos económicos (Unión Editorial, 1998). 
Esta es la clave para entender la razón por la que muchos economistas que se autodenominan «liberales» 38 recomiendan la intervención del sector público en materia monetaria, al considerar que las crisis y depresiones se deben tan solo a una contracción monetaria, «diagnóstico ingenuo y superficial que confunde la causa con el efecto, pues, como ya sabemos, las crisis económicas son resultado de la distorsión que sobre la estructura productiva generan previamente la expansión crediticia y la inflación, a lo largo de un complejo proceso que luego se manifiesta en forma de crisis, contracción de tipo monetario y recesión». 39

El enfoque austriaco sostiene que un aumento de los fondos prestables sin respaldo de ahorro real, estimula la inversión en proyectos que requieren más tiempo para su terminación del que los consumidores están dispuestos a esperar. Una expansión artificial del crédito — bajo una política monetaria laxa $-{ }^{40}$ provoca

38 Este problema es mucho mayor en el caso de los autores keynesianos, ya que los seguidores de las ideas de Lord Keynes suman a la falta de una teoría adecuada del capital y al uso de agregados una defensa encendida de la intervención del sector público en la vida de los ciudadanos. No es objeto de este trabajo entrar a fondo en las falacias del sistema keynesiano, pero sirva como apunte que, a diferencia de sus compañeros en el cultivo de la "macroeconomía» (los monetaristas), los keynesianos creen que el efecto de las políticas de expansión monetaria es relativamente pequeño en comparación con los de la política fiscal y preconizan un aumento de la demanda efectiva impulsado directamente por el gasto público. No entienden que tal política dificulta aún más el proceso de reajuste de la estructura productiva, agravando la situación de las etapas más alejadas del consumo, que pueden llegar a experimentar, como consecuencia de los «remedios» keynesianos, dificultades aún mayores para financiarse de forma permanente con cargo al ahorro voluntario.

39 Dinero, crédito bancario y ciclos económicos (Unión Editorial, 1998).

40 La teoría macroeconómica austriaca tiene sus raíces en la teoría monetaria de Knut Wicksell (1851-1926). Este economista sueco publicó en 1898 Interés y Precios, un trabajo en el que hizo su principal contribución a la economía al hablar de un «nivel natural» de la tasa de interés, que es la que corresponde a la estructura real de una economía. Si la tasa de interés de mercado monetario disminuye por debajo de la tasa natural, la demanda de dinero para invertir aumentará y los ahorros disminuirán, incrementando el consumo, todo lo que llevará a una expansión económica porque hay una expansión del crédito bancario. Los tipos de interés libremente determinados, ofrecen una señal fiable de hacia dónde debe dirigirse la producción, dadas las preferencias de consumo intertemporales de los agentes. Es decir, los tipos de interés coordinan los planes de producción de los empresarios y los patrones de consumo intertemporales de los perceptores de rentas, haciéndolos compatibles. La tasa de descuento intertemporal baja como consecuencia de que los individuos tienen más 
una descoordinación entre los planes de decisión de productores y consumidores, que se materializa en un exceso de inversión en proyectos a largo plazo que el mercado no será capaz de absorber. La estructura productiva sufre grandes distorsiones que no responden a las disponibilidades de recursos reales ni a las preferencias intertemporales de los consumidores, debiendo finalmente reajustarse (en la etapa de recesión) para que la economía vuelva a crecer de manera sostenible. Es decir, que es la etapa de boom artificial la que explica la existencia posterior de una caída de la actividad con elevados niveles de desempleo.

En la actualidad, la idea fatal keynesiana de que el paro se debe fundamentalmente a una insuficiencia de la demanda global ha vuelto a resurgir con fuerza. Como ya planteó Hayek en 1976, la popularidad de este enfoque se debe a sus implicaciones políticas, ya que «les ofrece a los políticos no solo un método rápido y barato de aliviar el sufrimiento humano, sino que también les alivia a ellos de aquellas molestas restricciones que les impiden alcanzar la popularidad. El gastar y los presupuestos deficitarios se consideran la representación de las virtudes. Se argumenta, persuasivamente, incluso, que el continuo gasto gubernamental es muy meritorio, dado que lleva a la utilización de recursos hasta entonces no usados y que esto no solo no cuesta nada a la comunidad, sino que aporta una ganancia neta. Estas creencias conducen, en particular, a un gradual desmantelamiento de todas las barreras al incremento de la cantidad de dinero por las autoridades monetarias. ( ... ) Pero la realidad es que «a largo plazo la inflación crea inevitablemente un paro mucho mayor que el que se pretendía evitar al principio. Es falso el argumento tantas veces oído de que la inflación produce meramente una redistribución del producto, mientras que el paro lo reduce, y que, por tanto, este último representa un mal grave. En realidad, la inflación es causa de un paro incrementado». ${ }^{41}$

preferencia por el futuro, es decir, tienen un mayor estímulo a ahorrar, los inversores están dispuestos a recibir menor recompensa por su ahorro presente a cambio de más consumo futuro. Si se manipulan los tipos de interés se produce una descoordinación generalizada.

${ }^{41}$ F.A. Hayek, Inflación o pleno empleo (Unión Editorial, Madrid 1976, cap. II). 
Siguiendo en análisis de Hayek, podemos afirmar que el peor de los daños causados por la inflación es la mala distribución del factor trabajo. La inflación crea temporalmente algunos puestos de trabajo que, sin embargo, desaparecen cuando se pasa aquélla o cuando disminuye su ritmo de aceleración. Esto es así porque la inflación cambia la distribución de dinero entre los diversos sectores y etapas del proceso de producción y, además, crea una expectativa de ulteriores subidas de precios. Y todo ello tiene unos efectos inevitables en la distribución del factor trabajo en las industrias y sobre la política salarial de los sindicatos:

«Tan pronto como el gobierno asume la responsabilidad de mantener el pleno empleo, sean cuales fueren los salarios que los sindicatos consiguen, entonces estos últimos se desentienden del paro que sus demandas salariales puedan producir. En esta situación, cada subida de jornales por encima del aumento de la productividad forzará un incremento de la demanda total si se quiere evitar el paro. El aumento de la cantidad de dinero provocado por esta escalada de salarios se convierte en un proceso continuo que exige nuevas y continuas sumas dinerarias adicionales. Esta oferta adicional de dinero conduce a cambios en la demanda relativa de los diversos bienes y servicios, lo que provoca ulteriores trastornos de los precios relativos en el curso de la producción y en la asignación de los factores de producción, entre ellos del trabajo». ${ }^{42}$

Por ello, continua Hayek, «cuanto más dure la inflación mayor será el número de trabajadores cuyos empleos dependerán de la continuación de la inflación, incluso, muy frecuentemente, de una aceleración continua de la misma, y ello no porque ellos se hubieran quedado cesantes en ausencia de inflación, sino porque fueron atraídos a trabajos que la inflación hizo temporalmente atractivos, pero que desaparecen tan pronto como cesa el ritmo de inflación o desaparece ésta. ( ... ) El intento de preservar esos puestos de trabajo creados por la inflación conduce a una destrucción total del mercado ( ... ) son exclusivamente nuestros propios errores, que la experiencia pasada y el conocimiento disponible

42 F.A. Hayek, Inflación o pleno empleo (Unión Editorial, Madrid 1976, cap. II). 
debieran habernos hecho evitar, los que nos traerán esta reaparición ineludible de un desempleo masivo, y no un fracaso del capitalismo o economía de mercado».

Por lo tanto, y como conclusión, coincidimos con Hayek en señalar que "es deber ineludible de todo economista que quiera hacer honor al título profesional que ostenta repetir, en cuantas ocasiones se le deparen, que el alto nivel de desempleo que hoy gravita sobre el mundo occidental es la directa e inevitable consecuencia de las denominadas políticas de "pleno empleo", que tanta popularidad han adquirido a lo largo de los últimos veinticinco años. La mayor parte de las gentes siguen aceptando el equivocado aserto según el cual un adecuado volumen de la demanda global permite absorber cualquier nivel de paro. Si se pretende realmente evitar que la irresistible presión de la opinión pública obligue a los respectivos gobiernos a lanzar de nuevo la inflación al menor atisbo de paro, es imprescindible que la opinión pública abandone de una vez para siempre tan equivocado aserto».43

IV

\section{UNA PROPUESTA DE REFORMA}

Ya estamos en condiciones de realizar una propuesta de reforma para lograr que el mercado laboral pueda autorregularse del mismo modo que lo haría cualquier otro proceso social en ausencia de coacción institucional. Sin embargo, antes de desglosar un listado de las recetas es necesario hacer una reflexión sobre cuál debe ser la metodología que guíe el paso de unas relaciones laborales intervenidas a un escenario en el que no exista injerencia de los poderes públicos.

Dentro de la Escuela Austriaca podríamos decir que existen dos tendencias a la hora de plantear reformas. Por un lado están aquellos que consideran que cualquier política legislativa - aunque implique una menor intervención- es una concesión al sistema coactivo y, por tanto, nunca será adecuada para lograr nuestro

${ }^{43}$ F.A. Hayek, Inflación o pleno empleo (Unión Editorial, Madrid 1976, cap. III). 
objetivo. Por otra parte, están aquellos que piensan que es necesario ir dando pequeños pasos en la retirada del sector público, mediante reformas que permitan más flexibilidad en los mercados.

En este trabajo consideramos más realista y pragmática la segunda opción, con la salvedad de que nunca debe perderse de vista el objetivo a perseguir. En muchas ocasiones existe el peligro de conformarse con pequeñas reformas liberalizadoras que lo único que consiguen es mantener el poder estatal sobre la vida de los ciudadanos, entorpeciendo las naturales relaciones de intercambio y produciendo graves distorsiones en la estructura productiva de la economía.

Atendiendo, por tanto, a esta segunda postura (la que propugna ir dando pequeños pero firmes pasos para ir avanzando en la liberalización), planteamos una serie de reformas del mercado de trabajo, cuyo fundamento se encuentra en el análisis previo que hemos realizado, relativo a las consecuencias que tienen las políticas públicas en materia laboral. Los objetivos finales que se deben perseguir pueden resumirse en los siguientes:

- Acabar con las regulaciones que establecen cualquier tipo de salario mínimo.

- Eliminar las cotizaciones sociales y cualquier carga fiscal sobre el empleo, realizando al mismo tiempo una reforma del sistema de Seguridad Social modificando el modelo actual de reparto para convertirlo en un sistema de capitalización en la que cada agente sea responsable de sus decisiones económicas que le permitan plantear su futuro sin la injerencia estatal. ${ }^{44}$

- Reducir el Impuesto sobre la Renta hasta el mínimo indispensable para poder ayudar a los incapacitados para trabajar. El objetivo final es eliminarlo, pero entendemos que primero es necesario culminar el punto anterior y fomentar el desarrollo de comunidades de asistencia privadas.

44 Una propuesta de reforma de la Seguridad Social en este sentido es la realizada por el profesor Huerta de Soto y que se encuentra publicada en The Theory of Dynamic Efficiency (Routledge, 2009). 
- Eliminar el Impuesto de Sociedades, pues lo único que hace es cercenar el capital indispensable para el desarrollo económico y, por ende, para la creación de empleo.

- Acabar con la negociación colectiva y con la financiación de los sindicatos mediante subvenciones. Las organizaciones deben ser independientes y obtener sus fondos de las personas que voluntariamente quieran pertenecer a ellas. Cualquier legislación que otorgue privilegios a estos grupos (así como a las patronales empresariales) también debe ser abolida.

- Permitir que los empresarios y trabajadores pacten individualmente los contratos, siendo libres de establecer todas las cláusulas, incluidas las relativas a una posible indemnización por despido.

- Desterrar el intervencionismo estatal en materia financiera, ya que la manipulación del sistema monetario es el responsable de que se produzcan ciclos recurrentes de auge y recesión que dan lugar a cifras de paro que, como en España, afectan a una cuarta parte de la población activa. En este sentido, como defiende el profesor Huerta de Soto «es imprescindible acabar con el privilegio que permite a los bancos operar con un coeficiente de reserva fraccionaría y expandir el crédito artificial creando ciclos económicos que acaban siempre generando descoordinación intertemporal, depresión y paro. Es vital someter a las entidades financieras a las normas y principios generales del derecho y, en particular, al coeficiente de $100 \%$ de reserva para los depósitos a la vista. La única forma de luchar contra el paro o desempleo consiste, por tanto, a corto plazo, en flexibilizar el mercado laboral en todos los sentidos, y a medio y largo plazo en evitar que se inicie proceso alguno de expansión artificial que tenga su origen en la concesión de créditos por parte del sistema bancario sin que previamente se haya producido un incremento del ahorro voluntario en la sociedad $\gg .45$

45 Sobre la importancia de respetar los principios generales del derecho en relación con el contrato de depósito irregular de dinero y sus repercusiones sobre la economía en general, y el mercado de trabajo en particular consultar: Jesús Huerta de Soto, Dinero, crédito bancario y ciclos económicos (Unión Editorial, 1998). 
Estas reformas de carácter económico deberían ir acompañadas por otras de tipo institucional, que permitan salvaguardar los derechos de propiedad de las personas, así como el intercambio libre de los bienes y servicios que emanan de este derecho.

En definitiva, lo que debe producirse es una vuelta a los principios generales del Derecho y al cumplimiento de las Leyes económicas que regulan ese gran orden espontáneo que Hayek denominó Gran Sociedad y que la teoría de la función empresarial identifica, en su sentido amplio, con el propio mercado.

Cualquier intento de intervenir mediante mandatos en el mercado laboral (como en los demás) lo único que provocará será empeorar la situación social que se pretende arreglar —en este caso el desempleo- y sentar las bases para posteriores planes de agresión institucional y sistemática que, lejos de reducir los desajustes, aumentará el grado de descoordinación entre las decisiones de los agentes económicos. En la medida en que nuestros gobernantes se den cuenta de ello y adquieran la formación teórica necesaria para llegar a las conclusiones que aquí exponemos serán capaces de detener un proceso que solo genera caos y destrucción. En caso contrario se mantendrá la existencia de ciclos económicos maniaco depresivos que generarán recesión y desempleo de forma recurrente. 
